Reprod. Nutr. Dévelop., 1980, 20 (1 B), 209-215.

\title{
Particular aspects of thyroid function development in the postnatal rat with special reference to interrelationships between mother and young
}

par E. VIGOUROUX, N. ROSTAQUI

Laboratoire de Physiologie comparée, LA no 307 du C.N.R.S, Université P.-et-M. Curie, 4, place Jussieu, 75230 Paris Cedex 05, France.

Summary. Previous data have demonstrated that thyroid gland thyroxine secretion rate in suckling rats is high and correlated with the hormonal needs of the young. Non-hormonal iodine metabolism is more elevated in the young than in the adult. The object of the present work was to measure rates of iodine transfer in 10-day old families of rats equilibrated with 125] or not. Reciprocal iodine exchange between mother and yound occurred in such a way that the dam recovered about 60 p. 100 of the iodine lost in the milk. Moreover, a large store of extrathyroidal iodine was constituted in the young, particularly in the pelt.

\section{Introduction.}

Thyroid hormones play an important role in the development of mammals. Brain maturation, for example, is highly thyroid-dependent (Eayrs, 1971 ; Legrand, 1977). The thyroxine secretion rate (TSR) in rats is high during the first two postnatal weeks (Vigouroux, 1976 ; Fisher et al., 1977). An excellent correlation has been established between the TSR and the thyroxine needs for normal maturation (Clos et al., 1974 ; Vigouroux, Clos and Legrand, 1979). Contrary to adult rats, the non-hormonal iodine metabolism in suckling rats quantitatively overlaps that of the thyroid hormones (Stolc, Knopp and Stolcova, 1973 ; Vigouroux, 1976) due to the high levels of nonhormonal iodine in the dam's milk which contains very little or no thyroid hormones (Hoskins, Van Arsdel and Williams, 1958 ; Vigouroux, Rostaqui and Fenerole, 1978). Moreover, Samel, Caputa and Struharova (1963) noted that a fraction of the radioiodine injected into suckling rats appeared in the dam's plasma. It is thus obvious that some iodine is transferred from the pups to the mother.

The aim of the present report is to study the role played by mother-young interrelations in the development of pup thyroid function. The converse iodine transfer rates (to the young from the dam) were analyzed on day 10 post-partum in rats isotopically equilibrated by ${ }^{125}$ or not. 


\section{Material and methods.}

Animals. - The Wistar rats used were fed a laboratory chow containing 0.4$0.6 \mu \mathrm{g}$ iodine/g. Isotopic equilibrium was obtained by adding ${ }^{125}$ to the drinking water as described by Vigouroux, Clos and Legrand (1979). Eight pups per family were used.

Non-radioactive iodine assay. - lodine was estimated in the diet, thyroid gland, plasma and urine by the ceric-arsenite reaction as previously described (Vigouroux, 1976). The iodine content of the pelt and the stomach was measured on dried fragments as for the diet ; it was calculated in the intestine, carcass and whole body of 125l-equilibrated rat pups using mean specific radioactivity (SA), estimated from the iodine SA in the plasma, thyroid, stomach, pelt and urine, i.e. $0.41 \pm 0.03(n=14), 0.48 \pm 0.02$

$$
\begin{aligned}
& \text { Rodioiodide injected } \begin{array}{c}
\text { into } \\
\text { MOTHER }
\end{array} \\
& q_{1}(0)=100 \text { p. } 100 \text { and } q_{2}(0)=0 \text { p. } 100 \quad q_{1}(0)=0 \text { p. } 100 \text { and } q_{2}(0)=100 \text { p. } 100 \\
& q_{1}=\frac{q_{1}(0)}{(a-b)}\left[\left(\lambda_{2}-b\right) e^{-b t}-\left(\lambda_{2}-a\right) e^{-a t}\right] \quad q_{1}=\frac{q_{2}(0)}{(a-b)} k_{12}\left(e^{-b t}-e^{-a t}\right) \\
& q_{2}=\frac{q_{1}(0)}{(a-b)} k_{21}\left(e^{-b t}-e^{-a t}\right) \quad \quad q_{2}=\frac{q_{2}(0)}{(a-b)}\left[\left(\lambda_{1}-b\right) e^{-b t}-\left(\lambda_{1}-a\right) e^{-a t}\right] \\
& q_{3}=\frac{q_{1}(0) k_{32} k_{21}}{a b(a-b)}\left[(a-b)+b e^{-a t}-a e^{-b t}\right] \quad q_{3}=\frac{q_{2}(0) k_{32}}{a b(a-b)}\left[\lambda_{1}(a-b)+b\left(\lambda_{1}-a\right) e^{-a t}-\overline{\left.a\left(\lambda_{1}-b\right) e^{-b t}\right]}\right. \\
& \begin{aligned}
q_{4}=\frac{q_{1}(0) k_{41}}{a b(a-b)}\left[\lambda_{2}(a-b)+\right. & b\left(\lambda_{2}-a\right) e^{-a t}-\overrightarrow{a t}=\frac{q_{2}(0) k_{41} k_{12}}{a b(a-b)}\left[(a-b)+b e^{-a t}-a e^{-b t}\right] \\
& \left.-a\left(\lambda_{2}-b\right) e^{-b t}\right]
\end{aligned} \\
& \lambda_{1}=k_{21}+k_{42}+k_{01} ; \lambda_{2}=k_{12}+k_{32}+k_{02} \\
& a, b=\frac{-\left(\lambda_{1}+\lambda_{2}\right) \pm \sqrt{\left(\lambda_{1}+\lambda_{2}\right)^{2}+4\left(k_{12} k_{21}-\lambda_{1} \lambda_{2}\right)}}{2}
\end{aligned}
$$

FIG. 1. - Theoretical and mathematical model for non-hormonal iodine metabolism in rat family on day 10 post-partum. Thick arrow indicates maternal dietary iodine uptake; $k$ symbols with subscripts are rate constants of iodine transfer to compartment 1 from compartment 2, to compartment 2 from compartment 1 , etc. ; $q$ symbols with subscripts show radioactivity of the compartments at a given time after radioiodide injection into the dam (left) or the pups (right); $q_{1}(0)$ and $q_{2}(0)$ are $q_{1}$ and $q_{2}$ at zero time. 
$(n=42), 0.42 \pm 0.02(n=42), 0.44 \pm 0.02(n=42)$ and $0.45 \pm 0.02 \mu \mathrm{Ci} / \mu \mathrm{g}$ iodine $(n=40)$, respectively.

lodine metabolism kinetics. - Either the dam or 4 of its offspring were given a subcutaneous tracerdose of radioiodide (131) in ${ }^{125}$ |-equilibrated rats ; ${ }^{131}$ or ${ }^{125}$ in nonequilibrated rats) ; they were killed at different times up to 24 hrs after injection. The ${ }^{125}$-equilibrated rats were killed at $24 \mathrm{hrs}$ only. Radioactivity was measured in the plasma, urine and thyroid of the mother and the young and in several organs and the whole body of the pups. Plasma radioiodide was estimated after extraction with trichloroacetic acid according to Vigouroux (1976).

The kinetic parameters were computed with reference to a theoretical mathematical model (fig. 1), taking into account the observations of Samel, Caputa and Struharova (1963). The system was assumed to be in steady state, i.e. the radioactivity taken up by the thyroid gland and accumulated in the pups was not released back into the blood in significant amounts during the short ferm of the experiments. The kinetic nomenclature and formulas used are those of Vigouroux (1976) : $\dagger$ represents the time interval after injection, and 0,1, 2, 3, 4 are parameter subscripts indicating the specific compartments. Compartments 1 and 2 represent the iodide equilibrated with plasma iodide in the dam and the pups, respectively, compartment 3 the iodine accumulated in the pup thyroid and other organs, and compartment 4 maternal thyroid iodine ; 0 indicates an extra-system compartment, particularly relating to iodine excretion.

Statistics. - The results were usually expressed with confidence limits (calculated by the propagation of errors method; Di Stefano et al., 1973) of $P=0.05$ for $n$ assays.

\section{Results.}

Two observations confirmed that iodine was transferred from the pups to the dam : (i) figure 2 shows that after injection of radioiodide into rat pups, the body radio-

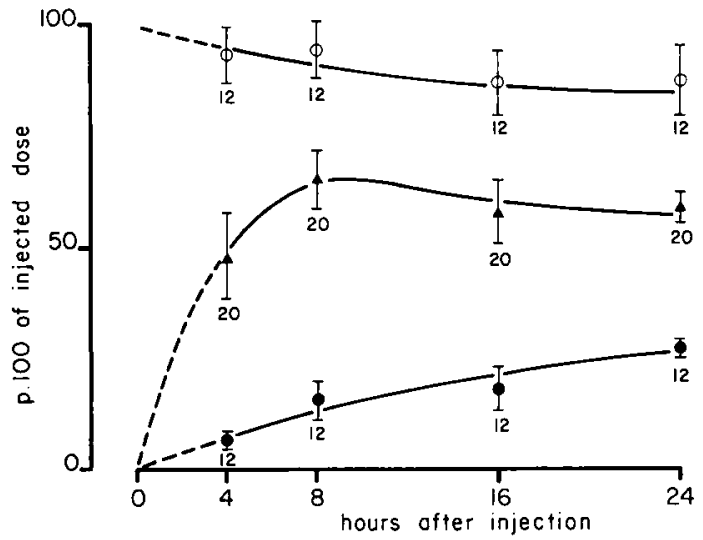

FIG. 2. - Sum of radioactivity in compartments 2 and 3 estimated from pup body radioactivity after injection of lobelled jodide into either the dam (middle curve) or the pups (upper curve). The recycled radiolodine (lower curve) of the pups is estimated from non-injected pups of the same litter. Vertical bars show confidence intervals of $P=0.05$. Number, $n$, is shown under the points. 
activity of the non-injected pups increased progressively. At 24 hrs the recycled radioiodine represented 27 p. 100 of the injected dose, indicating that the rate constant, $k_{12}$, was not less than a quarter of the constant $\lambda_{2}$; (ii) the plasma radioiodide clearance curve was not monoexponential in the dam given the tracer dose (fig. 3), suggesting that iodine was transferred from the pups to the dam. So, at 16 and 24 hrs, a fraction of maternal plasma radioactivity probably resulted from recycling through the pups.

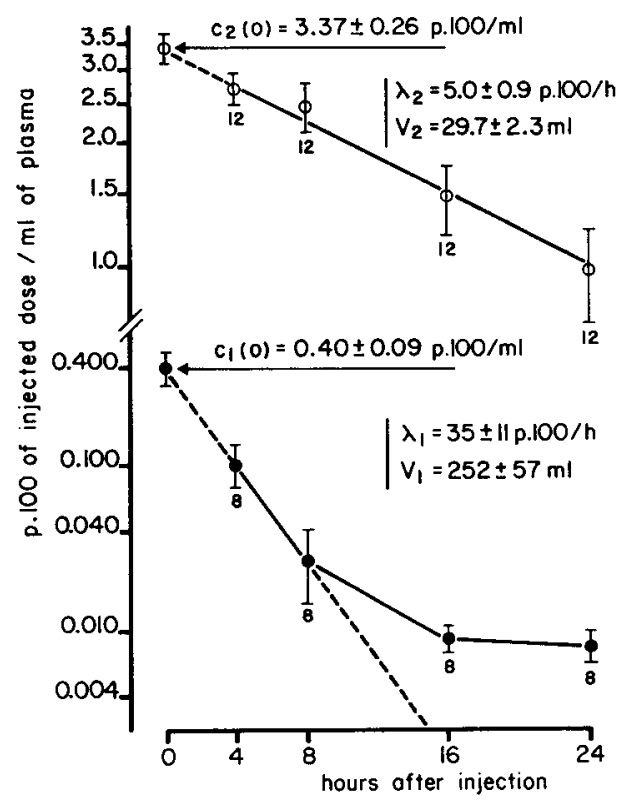

FIG. 3. - Plasma radioiodide clearance curves after injection of labelled $I^{-}$. Upper curve : plasma radioiodide of injected minus non-injected pups in the same litter. Lower curve : plasma radioiodide in injected dam. $c_{1}(0)$ and $c_{2}(0)=$ extrapolated concentrations at zero time ; rate constant $\lambda_{1}$ is estimated from the first two points of the dam's curve, and $\lambda_{2}$ from the total pup curve ; $V_{1}$ and $V_{2}=$ distribution volumes of unlabelled iodide in the dam and pups, respectively. For other explanations see text and figure 2 .

Kinetic results are given in table 1 . All the offspring in a litter were considered as a whole weighing $187 \pm 3 \mathrm{~g}(\mathrm{n}=249)$ as compared to their mother weighing $276 \pm 6 \mathrm{~g}$ $(n=37)$. lodine metabolism was distinctly more intense in the progeny than in the mother. There was no significant difference between maternal $Q_{4}$ and total pup thyroid iodine content $(9.8 \pm 0.7, n=42$ and $10.0 \pm 0.5 \mu \mathrm{g}$ iodine, $n=97$ in 125lequilibrated and non-equilibrated pups, respectively). The rate constant of thyroid uptake in pups was $0.6 \pm 0.2$ p. $100 / \mathrm{hr}(n=48)$ (significantly lower than $\left.k_{41}\right)$, but uptake rate was $3.8 \pm 1.4 \mu \mathrm{g}$ iodine/day (significantly higher than $R_{41}$ ). The return of iodine $R_{12}$ to the dam from its pups represented more than 60 p. 100 of the maternal $R_{21}$ supply. The iodine accumulation in compartment 3 was analyzed in detail in the ${ }^{125}$ equilibrated pups. At 24 hrs, $22 \pm 4(n=14)$ or $35 \pm 3$ p. $100(n=14)$ of the ${ }^{131}$ injected into the dam or its pups, respectively, was found in the pup pelt, whereas pup thyroid uptake was only $5.5 \pm 0.7$ or $10.7 \pm 3.8$ p. 100 , respectively. 
TABLE 1

Kinetic parameters

\begin{tabular}{lccc}
\hline \multicolumn{1}{c}{ Parameter } & Symbol & Value & Unif \\
\hline lodide distribution volume & $V_{1}$ & $252 \pm 57(16)$ & $\mathrm{ml}$ \\
& $V_{2}^{*}$ & $238 \pm 18(48)$ & $\mathrm{ng} \mathrm{I}-/ \mathrm{ml}$ \\
\hline Plasma iodide concentration & $\mathrm{C}_{1}$ & $11.6 \pm 2.3(29)$ & \\
\hline Amount of compartment iodine & $\mathrm{C}_{2}$ & $112 \pm 11(120)$ & $\mu$ g iodine \\
& $\mathrm{Q}_{1}$ & $2.9 \pm 0.9 * *$ & \\
& $\mathrm{Q}_{2}{ }^{*}$ & $26.6 \pm 3.4 * *$ & \\
\hline Rate constant & $\mathrm{Q}_{3}{ }^{*}$ & $40.5 \pm 7.1(42)$ & \\
& $\mathrm{Q}_{4}$ & $10.6 \pm 0.7(29)$ & \\
& $\lambda_{1}$ & $35 \pm 11(16)$ & \\
& $\mathrm{K}_{21}$ & $28[26-30]$ & \\
& $\mathrm{K}_{41}$ & $1.3 \pm 0.4(32)$ & \\
& $\lambda_{2}$ & $5.0 \pm 0.9(48)$ & \\
\hline Transfer rate & $\mathrm{K}_{12}$ & $1.8[1.6-2.0]$ & \\
& $\mathrm{K}_{32}$ & $2.0[1.6-2.4]$ & \\
& $\mathrm{R}_{21}$ & $19[13-25]$ & \\
& $\mathrm{R}_{12}$ & $12[10-14]$ & \\
& $\mathrm{R}_{32}$ & $13[11-15]$ & \\
& $\mathrm{R}_{41}$ & $0.9 \pm 0.5 * *$ & \\
\hline
\end{tabular}

* 8 times individual value.

** Product confidence limits calculated by the propagation of errors method.

) Number $n$.

] Boundary estimations of the parameter.

TABLE 2

Radioactivity (p. 100 of injected dose) in compartments 1, 2, 3, 4 after injection of radioiodide into dam (A) or 10-day old rat pups (B) as a function of time (hrs)

\begin{tabular}{|c|c|c|c|c|c|c|c|c|c|}
\hline & \multirow{2}{*}{$\begin{array}{c}\text { Time } \\
\\
4 \\
8 \\
16 \\
24\end{array}$} & \multicolumn{2}{|c|}{$q_{1}$} & \multicolumn{2}{|c|}{$q_{2}$} & \multicolumn{2}{|c|}{$q_{3}$} & \multicolumn{2}{|c|}{$q_{l}$} \\
\hline A & & $\begin{array}{r}26.3 \\
8.8 \\
3.1 \\
2.1\end{array}$ & $\begin{array}{c}26.0 \\
6.8 \\
2.2 \\
2.0 \\
{[2.8]}\end{array}$ & $\begin{array}{l}54.1 \\
59.7 \\
48.7 \\
37.2\end{array}$ & $\begin{array}{c}44.5 \\
60.6 \\
47.1 \\
40.0 \\
{[38.5]}\end{array}$ & $\begin{array}{r}2.8 \\
7.5 \\
16.2 \\
23.1\end{array}$ & $\begin{array}{c}3.3 \\
4.5 \\
10.5 \\
18.6 \\
{[20.9]}\end{array}$ & $\begin{array}{l}2.8 \\
3.6 \\
4.1 \\
4.4\end{array}$ & $\begin{array}{c}3.5 \\
3.4 \\
3.6 \\
4.0 \\
{[5.4]}\end{array}$ \\
\hline B & $\begin{array}{r}4 \\
8 \\
16 \\
24\end{array}$ & $\begin{array}{l}3.5 \\
3.8 \\
3.1 \\
2.4\end{array}$ & $\begin{array}{c}6.3 \\
6.8 \\
2.5 \\
2.3 \\
{[2.8]}\end{array}$ & $\begin{array}{l}84.2 \\
72.8 \\
55.2 \\
42.0\end{array}$ & $\begin{array}{c}84.2 \\
83.7 \\
55.1 \\
46.8 \\
{[39.6]}\end{array}$ & $\begin{array}{r}7.3 \\
13.6 \\
23.7 \\
31.5\end{array}$ & $\begin{array}{r}8.8 \\
10.2 \\
31.4 \\
39.7 \\
{[41.3]}\end{array}$ & $\begin{array}{l}0.1 \\
0.3 \\
0.7 \\
1.0\end{array}$ & $\begin{array}{l}0.2 \\
0.7 \\
0.5 \\
1.2 \\
{[1.6]}\end{array}$ \\
\hline
\end{tabular}

The values in column 1 of each compartment are computed using figure 1 formulas ; column 2 values are computed as follows : $q_{1}=V_{1} \times$ plasma radioiodide content in dam, $q_{2}=V_{2} \times$ plasma radioiodide content in pups, $q_{3}=$ pup body radioactivity minus $q_{2}$, and $q_{4}=$ maternal thyroid acti-

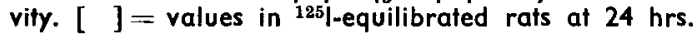


The radioactivity in the different compartments was calculated by inserting the mean values of table 1 into the formulas of figure 1 (table 2). They were not significantly different from the experimental data. This constitutes a strong argument in favor of the validity of the methodology used.

\section{Discussion and conclusion.}

The present results confirm that iodine is transferred from suckling rat pups to their mother. This quantitatively important process may be explained by the fact that the dam eats the excreta of its offspring. Micturation in the suckling rat is not interoceptively regulated (Capek and Jelinek, 1956); it is an extraoceptive reflex, i.e. the dam licks the perianal area. Such a mechanism recycles the substances excreted by the pups and may be important, not only as regards iodine, but also for many other elements. For example, by the same mechanism lactating mothers of various desert mammals recover more than 50 p. 100 of the water lost in the milk (Baverstock and Green, 1975).

All our results on the formation of an iodine store in rat pups have not been discussed here but will be published later. The present data on compartment 3 are in agreement with those of Brown-Grant and Pethes (1959), Stolc, Knopp and Stolcova (1973) and Vigouroux (1976) showing that iodine uptake by extrathyroidal tissues, and particularly by the skin, is much higher in suckling pups than in adult rats. From postnatal week 3 , the suckling rat progressively replaces the dam's milk, which has a high iodine content (Vigouroux, Rostaqui and Fenerole, 1978), by an iodine-pcor diet. This occurs while thyroxine secretion rate is still intense (Clos et al., 1974 ; Vigouroux, 1976). The thyroid of the pups may use the iodine accumulated in the pelt and other organs. Thus, an apparent luxury becomes a judicious prevision.

5e Réunion du groupe Développement I.N.R.A., Clermont-Ferrand/Theix, 17-18 mai 1979.

Acknowledgements. - This study was supported by the Délégation Générale à la Recherche Scientifique ef Technique (France), contracts no. 75-7-1325 and 77-7-0965.

Résumé. Des résultats antérieurs obtenus chez des rats non sevrés ont établi l'existence d'une intense sécrétion de thyroxine par la thyroïde pouvant être mise en relation avec des besoins en hormone et d'un métabolisme de l'iode non hormonal particulièrement importants chez les jeunes par rapport à l'adulte. Le but de ce travail est de mesurer chez des rats équilibrés ou non par ${ }^{125}$ les flux d'iode au sein de la cellule familiale à 10 jours post-partum. Entre la mère et l'ensemble des jeunes se créent des échanges bidirectionnels tels que la mère récupère environ 60 p. 100 de l'iode fourni par le lait. En outre les jeunes réalisent d'énormes réserves d'iode extrathyroïdien particulièrement au niveau de la peau.

\section{References}

BAVERSTOCK P., GREEN B., 1975. Water recycling in lactation. Science, 187, 657-658.

BROWN-GRANT K., PETHES G., 1959. Concentration of radio-iodide in the skin of the rat. J. Physiol., 148, 683-693.

CAPEK K., JELINEK J., 1956. The development of the control of water metabolism. 1. - The excretion of urine in young rats. Physiol. bohemoslov., 5, 91-96. 
CLOS J., CREPEL F., LEGRAND C., LEGRAND J., RABIE A., VIGOUROUX E., 1974. Thyroid physiology during the postnatal period in the rat : A study of the development of thyroid function and of the morphogenetic effects of thyroxine with special reference to cerebellar maturation. Gen. comp. Endacr., 23, 178-192.

DI STEFANO J. J., DURANDO A. R., JANG M., JENKINS D., JOHNSON D. J., MAK P., MARSHALL T., MONS B., WARSAVSKY A., FISHER D. A., 1973. Estimates and estimation errors of hormone secretion, transport and disposal rates in the maternal-fetal system. Endocrinology, 93, 324-342.

EAYRS J. T., 1971. Thyroid and developing brain : anatomical and behavioural effects, 345.355. In HAMBURGH M., BARRINGTON E. J. W., Hormones in development, Appleton Century Crofts, New York.

FISHER D. A., DUSSAULT J. H., SACK J., CHOPRA I. J., 1977. Ontogenesis of hypothalamic-pituitarythyroid function and metabolism in man, sheep and rat. Recent Progr. Horm. Res., 33, 59-116.

HOSKINS L. C., VAN ARSDEL P. P., WILLIAMS R. H., 1958. Placental transmission and mammary gland secretion of thyroxin in the rat. Am. J. Physiol., 193, 509-512.

LEGRAND J., 1977. Morphologic and biochemical effects of hormones on the developing nervous system in mammals, 137-164. In BERENBERG S. R., Brain, fetal and infant. Current research on normal and abnormal development, Martinus Nijhoff Medical Division, The Hague.

SAMEL M., CAPUTA A., STRUHAROVA L., 1963. Extrauterine recirculation of iodine-131 from the young to mother in rats. Nature, 198, 489.

STOLC V., KNOPP J., STOLCOVA E., 1973. lodine concentration and content in the organs of rat during postnatal development. Biol. Neonate, 23, 35-44.

VIGOUROUX E., 1976. Dynamic study of post-natal thyroid function in the rat. Acta endocr., 83, 752762.

VIGOUROUX E., CLOS J., LEGRAND J., 1979. Uptake and metabolism of exogenous and endogenous thyroxine in the brain of young rats. Horm. Metab. Res., 11, 228-232.

VIGOUROUX E., ROSTAQUI N., FENEROLE J. M., 1978. Etude du transfert de l'iode de la mère au jeune rat par le lait maternel. J. Physiol. (Paris), 74, 49A. 